УДК 339.187.62:631.115:332.27

https://doi.org/10.47612/978-985-7149-55-1-2020-166-170

Валерий Метлицкий, кандидат экономических наук, ведущий научный сотрудник

Мария Нескребина, научный сотрудник

Институт системных исследований в АПК НАН Беларуси, г. Минск

\title{
Институциональная модель передачи \\ в лизинг неплатежеспособной сельскохозяйственной организации как имущественного комплекса
}

По мнению некоторых исследователей $[1,2]$, лизинг является эффективным финансовым инструментом модернизации экономики. Благодаря развитию лизинговых услуг создаются новые точки роста экономики, в частности, лизинг позволяет более активно развиваться малым и средним предприятиям, модернизировать производство, а также продвигать отечественную продукцию как на внутреннем, так и на внешних рынках (благодаря инструменту международного лизинга).

Очевидно, что лизинг является многофункциональным и гибким инструментом, который одновременно обладает чертами различных имущественных отношений: кредитования, аренды, аренды с правом выкупа, доверительного управления. Данная особенность позволяет модернизировать инструмент лизинга и использовать его для финансирования программ различного масштаба, в том числе проектов по приобретению предприятий как имущественных комплексов.

В статье 636 Гражданского кодекса Республики Беларусь (далее - ГК) дано определение лизинга: «По договору финансовой аренды (лизинга) (далее - договор финансовой аренды) арендодатель (лизингодатель), являющийся юридическим лицом или индивидуальным предпринимателем, обязуется приобрести в собственность указанное арендатором (лизингополучателем) имущество у определенного им продавца (поставщика) и предоставить арендатору (лизингополучателю) это имущество, составляющее предмет договора финансовой аренды, за плату во временное владение и пользование» [3].

Согласно ГК, предметом договора финансовой аренды (лизинга) могут быть любые непотребляемые вещи, кроме земельных участков и других природных объектов. Однако в сравнении с лизингом список объектов аренды шире. Так, в аренду могут быть переданы земельные участки и другие обособленные природные объекты, предприятия и иные имущественные комплексы, капитальные строения (здания, сооружения), изолированные помещения, машино-места, их части, определенные сторонами в договоре, оборудование, транспортные средства и другие вещи, которые не теряют своих натуральных свойств в процессе их использования (непотребляемые вещи) [3].

Предметом лизинга могут быть предприятия и другие имущественные комплексы. Предприятие может быть предметом как финансового, так и возвратного и оперативного лизинга, каких-либо ограничений по видам лизинга для предприятий законодательством не предусмотрено. Общим для всех видов лизинга будет то, что, реализуя лизинговую сделку лизингодателю, сначала надо будет приобрести данное предприятие в свою собственность либо сдавать в лизинг ранее приобретенное предприятие.

В статье 637 ГК «Предмет договора финансовой аренды», как описано выше, не запрещена передача в финансовую аренду (лизинг) предприятий. Кроме того, в соответствии со статьей 132 ГК предприятием как объектом признается имущественный комплекс, который используется для осуществления предпринимательской деятельности. Таким образом, для целей заключения договоров лизинга использование предприятия как имущественного комплекса в качестве предмета лизинга не противоречит целям инвестиционного лизинга.

Общей характеристикой для всех видов лизинга предприятий (за возможным исключением оперативного лизинга) станет относительно длительный срок договора лизинга (не менее трех лет), так как данный инвестиционный проект не сможет окупиться в краткосрочном периоде. Исключение составляет оперативный лизинг, при котором лизинговая организация за срок эксплуатации предмета лизинга может передавать его лизингополучателям несколько раз, так как именно данный вид лизинга не подразумевает выкуп имущества по окончании действия договора.

Таким образом, при передаче государственного предприятия в лизинг через государственную лизинговую организацию существует возможность контролировать нового владельца (лизингополучателя) в части выполнения взятых им социальных обязательств, сохранения трудового коллектива и развития предприятия. С одной стороны, лизингополучатель приобретает в лизинг предприятие как единое целое, включая и трудовые ресурсы, с целью получения прибыли. С другой стороны, государство ответственно за социальную обстановку, которая будет складываться на предприятии, прежде всего за численность сотрудников, финансовые условия работы и др. В связи с этим в договоре лизинга необходимо прописывать определенные обязанности лизингополучателя по сохранению стабильной социальной обстановки. Однако, как и любой другой фактор производства, трудовые ресурсы должны, прежде всего, соответствовать стратегии бизнеса. Вследствие этого ограничения лизингополучателя должны быть гибкими и соответствовать экономической и технологической обстановке на предприятии. 
Отличием лизинга от аренды является то, что лизингодатель, являющийся юридическим лицом либо индивидуальным предпринимателем, обязуется приобрести в собственность указанное арендатором (лизингополучателем) имущество у определенного им продавца (поставщика) и предоставить арендатору (лизингополучателю) это имущество, составляющее предмет договора финансовой аренды, за плату во временное владение и пользование. То есть фактически в договоре участвуют три стороны:

1) организация-владелец имущественного комплекса;

2) лизингодатель;

3) лизингополучатель

Также отличие от аренды в том, что на условиях лизинга невозможно передавать некоторые непотребляемые объекты: сельскохозяйственные угодья, природные объекты и т. д. и в случае передачи имущественного комплекса сельскохозяйственной организации в лизинг дополнительно необходимо заключение договоров аренды этих объектов.

Механизм, который может быть использован в случае передачи в лизинг имущественного комплекса неплатежеспособной сельскохозяйственной организации, показан на рисунке.

Алгоритм действий при заключении договора лизинга заключается в следующем:

1) лизингополучатель находит сельскохозяйственную организацию, имущественный комплекс которой он желает приобрести в лизинг, и узнает, согласен ли владелец продать свое имущество;

2) лизингополучатель обращается к лизингодателю (часто в этой роли выступает банк, имеющий право осуществлять лизинговую деятельность) с просьбой приобрести выбранный им имущественный комплекс, а затем передать в лизинг. В случае согласия подписывается лизинговый договор;
3) лизингодатель оформляет договор купли-продажи с продавцом имущества, собственником объекта лизинга становится лизингодатель;

4) лизингодатель передает имущественный комплекс лизингополучателю;

5) лизингополучатель совершает лизинговые платежи до окончания срока действия договора. Срок лизинга устанавливается договором;

6) по истечении срока лизинга лизингополучатель выкупает имущественный комплекс по установленной выкупной стоимости.

Модель лизинга имущественного комплекса сельскохозяйственной организации можно представить в следующем виде:

$$
\text { Л }=\mathrm{A}+\sum_{n}^{1} \frac{\mathrm{C}-\mathrm{A}-\mathrm{B}_{\mathrm{c}}}{n}+\sum_{i}^{1} \mathrm{O}_{i} \times \mathrm{C}_{\text {л }}+\mathrm{B}_{\mathrm{c}}+\mathrm{HДC},
$$

где Л - размер лизинговых платежей;

A - размер авансового платежа;

$\mathrm{C}$ - стоимость объекта лизинга;

$\mathrm{O}_{i}$ - остаточная стоимость лизинга $i$-го периода;

$\mathrm{C}_{\text {л }}$ - ставка лизинга, \%;

$\mathrm{B}_{\text {с }}$ - выкупная стоимость;

$n$ - количество периодов лизинговых платежей;

НДС - налог на добавленную стоимость.

Размер лизинговых платежей - та сумма средств, которую выплачивает лизингополучатель лизинговой компании за имущественный комплекс предприятия.

Размер авансового платежа - установленный в процессе переговоров с лизинговой компанией размер первоначальной оплаты имущественного комплекса в процентах.

Стоимость объекта лизинга - стоимость имущества, оговоренная в договоре лизинга - сумма краткосрочных и долгосрочных активов организации (строки 190 и 290 бухгалтерского баланса).

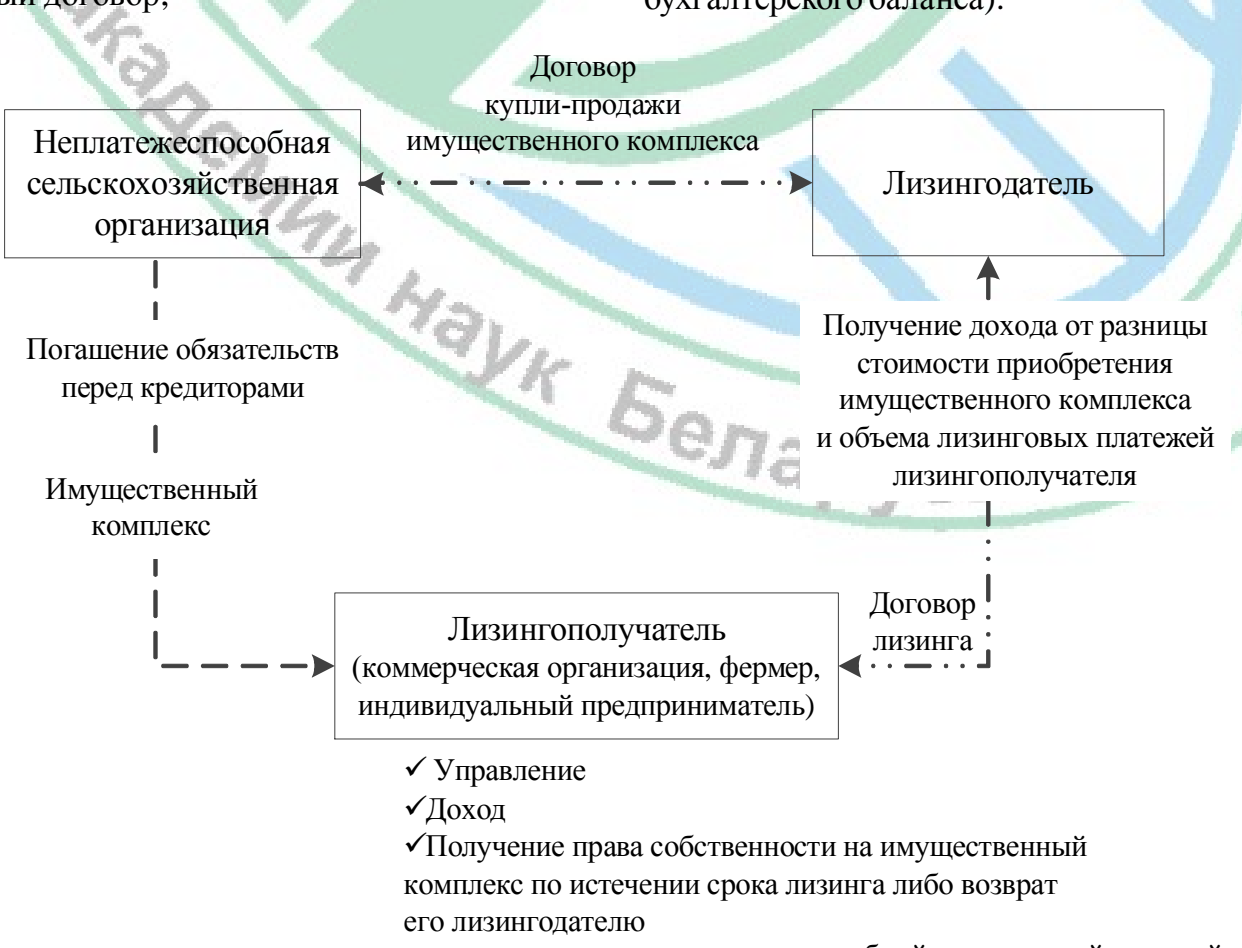

Рис. Механизм передачи в лизинг имущественного комплекса неплатежеспособной сельскохозяйственной организации 
Остаточная стоимость лизинга i-го периода расчетная величина стоимости имущества, необходимая для расчета лизингового платежа, представляющая стоимость объекта лизинга за вычетом ее части, выплаченной в $i$-м периоде, рассчитанная по формуле

$$
\mathrm{O}_{i}=\left(\mathrm{C}-\mathrm{A}-\mathrm{B}_{\mathrm{c}}\right)-\sum_{i}^{1} \frac{\mathrm{C}-\mathrm{A}-\mathrm{B}_{\mathrm{c}}}{n}
$$

Ставка лизинга - установленный в процессе заключения договора лизинга процент от остаточной стоимости лизинговых платежей, используемый для расчета лизингового платежа.

Выкупная стоимость - установленный в процессе заключения договора процент от стоимости объекта лизинга, по которому лизингополучатель приобретает у лизингодателя имущественный комплекс после окончания периода лизинга.

Количество периодов платежей - число периодов оплаты, установленное в договоре лизинга.

При передаче имущественного комплекса неплатежеспособной организации в лизинг происходит продажа его лизинговой компании и погашение за счет полученных средств от продажи обязательств организации перед кредиторами. В дальнейшем происходит возмещение затрат лизинговой компании за счет лизинговых платежей лизингополучателя.

Срок лизинга у некоторых отечественных лизинговых компаний может составлять от 1 до 5 лет (по легковым автомобилям - до 3 лет включительно, по недвижимости - до 7 лет включительно) [8].

Стандартный размер авансового платежа (первоначального взноса) может составлять от $20 \%$ от стоимости предмета лизинга [8]. В соответствии с законодательством Республики Беларусь размер собственного участия не может превышать $40 \%$.

Все расчеты по договору лизинга лизинговые компании могут производить по курсу Национального банка Республики Беларусь.

Объект лизинга подлежит страхованию от всех рисков, что является дополнительными затратами.

Сравним модели передачи в аренду и лизинг имущественного комплекса сельскохозяйственной организации.
Вариант 1. Аренда имущественного комплекса.

Рассмотрим вариант с арендной ставкой, равной $5 \%$ от балансовой стоимости в год и последующим выкупом организации. Срок аренды 5 лет. Балансовая стоимость имущественного комплекса равна 19737000 руб. (табл. 1).

Вариант 2. Лизинг предприятия как имущуественного комплекса.

Для данной модели лизинга возможен следующий вариант: процентная ставка 9 \% годовых. Авансовый платеж равен $20 \%$. Остаточная выкупная стоимость равна $1 \%$. Для предприятия как имущественного комплекса, включающего здания и сооружения, машины и оборудование и прочие объекты, срок лизинга составит 5 лет. Балансовая стоимость имущественного комплекса равна 19737000 руб. (табл. 2). Общее удорожание за срок лизинга составляет $22,2 \%$.

При лизинге предприятия как имущественного комплекса происходит постепенное снижение лизинговых платежей по мере выплаты стоимости объекта лизинга, чего не происходит при аренде имущественного комплекса, поэтому даже при большей процентной ставке по лизингу, равной $9 \%$, итоговая стоимость выкупа имущественного комплекса может быть ниже, чем при аренде с последующим выкупом.

Следует учитывать особенности расторжения договоров. Расторжение договора аренды имущественного комплекса менее затратное в случае, если возникает необходимость расторгнуть договор аренды и имущественный комплекс передать арендодателю. В случае возврата имущественного комплекса по договору лизинга лизингополучатель за период лизинга уже выплачивает часть стоимости имущественного комплекса, которую лизинговая компания не компенсирует.

Следует отметить, что согласно Указу Президента Республики Беларусь от 2 октября 2018 г. № 399 «О финансовом оздоровлении сельскохозяйственных организаций» для сельскохозяйственных организаций, подлежащих финансовому оздоровлению, установлено, что предложение о цене продажи имущественного комплекса сельскохозяйственных организаций (хозяйственных обществ) формируется на первое число квартала,

Таблица 1. Стоимость аренды имущественного комплекса сельскохозяйственной организации, руб.

\begin{tabular}{|c|c|c|c|}
\hline \multirow{2}{*}{ Номер платежа } & \multicolumn{2}{|c|}{ Арендная плата (5 \% от балансовой стоимости) } & \multirow{2}{*}{$\begin{array}{c}\text { Всего платежей } \\
\text { с НДС }\end{array}$} \\
\hline & Сумма без НДС & 6 Сумма НДС $(20 \%)$ & \\
\hline Балансовая стоимость & 19737000 & 0 & +2 \\
\hline 1 месяц & 82238 & 16448 & 98685 \\
\hline 2 месяц & 82238 & 16448 & 98685 \\
\hline 3 месяц & 82238 & 16448 & 98685 \\
\hline 4 месяц & 82238 & 16448 & 98685 \\
\hline 5 месяц & 82238 & 16448 & 98685 \\
\hline$\ldots$ & $\ldots$ & $\ldots$ & $\ldots$ \\
\hline 57 месяц & 82238 & 16448 & 98685 \\
\hline 58 месяц & 82238 & 16448 & 98685 \\
\hline 59 месяц & 82238 & 16448 & 98685 \\
\hline 60 месяц & 82238 & 16448 & 98685 \\
\hline Итого & 4934250 & 986850 & 5921100 \\
\hline Выкупная стоимость (100 \%) & 16283025 & 3256605 & 19737000 \\
\hline
\end{tabular}


Таблица 2. Стоимость лизинга имущественного комплекса сельскохозяйственной организации, руб.

\begin{tabular}{|c|c|c|c|c|c|c|c|}
\hline \multirow{2}{*}{$\begin{array}{c}\text { Номер } \\
\text { платежа }\end{array}$} & \multicolumn{2}{|c|}{ Возмещение стоимости } & \multicolumn{2}{|c|}{ Ставка по лизингу } & \multicolumn{2}{|c|}{ Лизинговый платеж } & \multirow{2}{*}{$\begin{array}{l}\text { Всего пла- } \\
\text { тежей с НДС }\end{array}$} \\
\hline & $\begin{array}{c}\text { Сумма без } \\
\text { НДС }\end{array}$ & Сумма НДС & $\begin{array}{c}\text { Сумма без } \\
\text { НДС }\end{array}$ & Сумма НДС & $\begin{array}{c}\text { Сумма без } \\
\text { НДС }\end{array}$ & Сумма НДС & \\
\hline Аванс & 3289500 & 657900 & 0 & 0 & 3289500 & 657900 & 3947400 \\
\hline 1 месяц & 216559 & 43312 & 118422 & 23684 & 334981 & 66996 & 401977 \\
\hline 2 месяц & 216559 & 43312 & 116473 & 23295 & 333032 & 66607 & 399639 \\
\hline 3 месяц & 216559 & 43312 & 114524 & 22905 & 331083 & 66217 & 397300 \\
\hline 4 месяц & 216559 & 43312 & 112575 & 22515 & 329134 & 65827 & 394961 \\
\hline 5 месяц & 216559 & 43312 & 110626 & 22125 & 327185 & 65437 & 392622 \\
\hline$\ldots$ & $\ldots$ & $\ldots$ & $\ldots$ & $\ldots$ & 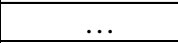 & $\ldots$ & $\ldots$ \\
\hline 57 месяц & 216559 & -43312 & 9276 & 1855 & 225835 & 45167 & 271002 \\
\hline 58 месяц & 216559 & 43312 & $\begin{array}{l}7327 \\
\end{array}$ & $\begin{array}{r}1465 \\
\end{array}$ & 223886 & 44777 & 268663 \\
\hline 59 месяц & 216559 & 43312 & 5378 & 1076 & 221937 & 44388 & 266325 \\
\hline 60 месяц & 216544 & 43297 & 3429 & 685 & 219973 & 43982 & 263955 \\
\hline Итого & 16283025 & 3256605 & 3655536 & 731107 & \begin{tabular}{|l|}
19938561 \\
\end{tabular} & 3987712 & 23926273 \\
\hline $\begin{array}{c}\text { Остаточная } \\
\text { выкупная сто- } \\
\text { имость (1 \%) }\end{array}$ & 164475 & 32895 & - & & & - & 197370 \\
\hline
\end{tabular}

в котором принято решение о сдаче имущественного комплекса в аренду, исходя из:

$\checkmark$ рыночной стоимости;

$\checkmark$ оценочной стоимости - для имущественных комплексов сельскохозяйственных организаций (хозяйственных обществ), у которых в течение последних трех лет, предшествующих 1 января года, в котором эта организация включена в перечень, сложился положительный финансовый результат от реализации продукции, товаров (работ, услуг) и не образовался чистый убыток.

При этом цена продажи имущественного комплекса неплатежеспособной сельскохозяйственной организации, сданного в аренду, может быть снижена до:

$\checkmark 20 \%$ от оценочной стоимости - для имущественных комплексов сельскохозяйственных организаций (хозяйственных обществ), у которых в течение последних трех лет, предшествующих 1 января года, в котором эта организация включена в перечень, сложился отрицательный финансовый результат от реализации продукции, товаров (работ, услуг) и (или) образовался чистый убыток;

$\checkmark 50 \%$ от оценочной стоимости - для имущественных комплексов сельскохозяйственных организаций (хозяйственных обществ), у которых в течение последних трех лет, предшествующих 1 января года, в котором эта организация включена в перечень, в двух годах сложился отрицательный финансовый результат от реализации продукции, товаров (работ, услуг) и (или) образовался чистый убыток;

$\checkmark 80 \%$ от оценочной стоимости - для имущественных комплексов сельскохозяйственных организаций (хозяйственных обществ), у которых в течение последних трех лет, предшествующих 1 января года, в котором эта организация включена в перечень, в одном году сложился отрицательный финансовый результат от реализации продукции, товаров (работ, услуг) и (или) образовался чистый убыток [6].

При передаче имущественного комплекса неплатежеспособной организации в лизинг происходит продажа ее инвестору, и из средств, полученных от продажи (лизинговых платежей), осуществляется возмещение обязательств организации перед кредиторами.

В случае снижения цены выкупа при приобретении имущественного комплекса при передаче предприятия в аренду она имеет более выгодные условия для инвестора, чем лизинг (табл. 3).

Преимуществом лизинга в сравнении с договором аренды является то, что договор позволяет возместить обязательства продаваемой организации в короткие сроки за счет средств от ее продажи лизингодателю и распределить платежи лизингополучателя за имущественный комплекс на срок действия договора лизинга. Недостатком лизинга является то, что в итоге стоимость имущественного комплекса будет выше, чем при заключении сделки купли-продажи, но при этом размер ежегодных лизинговых платежей будет меньше.

Вместе с тем с позиции инвестора институциональная модель лизинга предприятия как имущественного комплекса более выгодна в случаях, если в дальнейшем планируется выкуп имущественного комплекса по полной оценочной или рыночной стоимости. Данные особенности позволяют модернизировать инструмент лизинга и использовать его для финансирования программ

Таблица 3. Сравнение удорожания для инвестора аренды с последующим выкупом и лизинга имущественного комплекса сельскохозяйственной организации

\begin{tabular}{|c|c|c|c|c|c|}
\hline Вариант & $\begin{array}{c}\text { Балансовая } \\
\text { стоимость, руб. }\end{array}$ & НДС, руб. & $\begin{array}{c}\text { Платежи } \\
\text { за } 60 \text { месяцев, руб. }\end{array}$ & $\begin{array}{c}\text { Выкупная } \\
\text { стоимость, \% } \\
\end{array}$ & $\begin{array}{c}\text { Удорожание, } \\
\% \\
\end{array}$ \\
\hline \multirow{4}{*}{ Аренда } & \multirow{4}{*}{19737000} & \multirow{4}{*}{986850} & \multirow{4}{*}{5921100} & 100 & 30,0 \\
\hline & & & & 80 & 10,0 \\
\hline & & & & 50 & $-20,0$ \\
\hline & & & & 20 & $-50,0$ \\
\hline Лизинг & 19737000 & 3987712 & 23926273 & 1 & 22,2 \\
\hline
\end{tabular}


различного масштаба, в том числе проектов по приобретению предприятий как имущественных комплексов посредством инструмента лизинга.

Именно инструмент лизинга неплатежеспособной сельскохозяйственной организации как имущественного комплекса может стать достойной альтернативой аренды с дальнейшим выкупом.

\section{Список использованных источников}

1. Дедков, А. О лизинге предприятия как имущественного комплекса в свете приватизации государственной собственности / А. Дедков // Банковский вестн. 2016. -№ 11. - С. 62-67.

2. Кисельков, Н. Лизинг предприятия как имущественного комплекса в Республике Беларусь / Н. Кисельков // Банковский вестн. - 2016. - № 11. - С. 55-61.

3. Гражданский кодекс Республики Беларусь [Электронный ресурс] // КонсультантПлюс: Беларусь / ООО «ЮрСпектр», Нац. центр правовой информ. Респ. Беларусь. - Минск, 2019.

4. О вопросах регулирования лизинговой деятельности [Электронный ресурс] : Указ Президента Респ.
Беларусь, 25 февр. 2014 г., № 99. - Режим доступа: http:// www.pravo.by/main.aspx?guid=3871\&p0=P31400099. Дата доступа: 07.02.2016.

5. Об утверждении Правил осуществления лизинговой деятельности [Электронный ресурс] : постановление Правления Национального банка Респ. Беларусь, 18 авг. 2014 г., № 526. - Режим доступа: http://www. nbrb.by/Legislation/ documents/P_526.pdf. - Дата доступа: 07.03.2016.

6. О финансовом оздоровлении сельскохозяйственных организаций [Электронный ресурс] : Указ Президента Респ. Беларусь, 2 окт. 2018 г., № 399 // Консультант-Плюс: Беларусь. Версия 4016.00.07 / ООО «ЮрСпектр», Нац. центр правовой информ. Респ. Беларусь. - Минск, 2019.

7. Перечень постатейных переводов к Гражданскому кодексу Республики Беларусь [Электронный ресурс] // КонсультантПлюс: Беларусь / ООО «ЮрСпектр», Нац. центр правовой информ. Респ. Беларусь. - Минск, 2019.

8. Райффайзен-Лизинг [Электронный ресурс]. Режим доступа: http://www.rl.by. - Дата доступа: 03.03.2020.

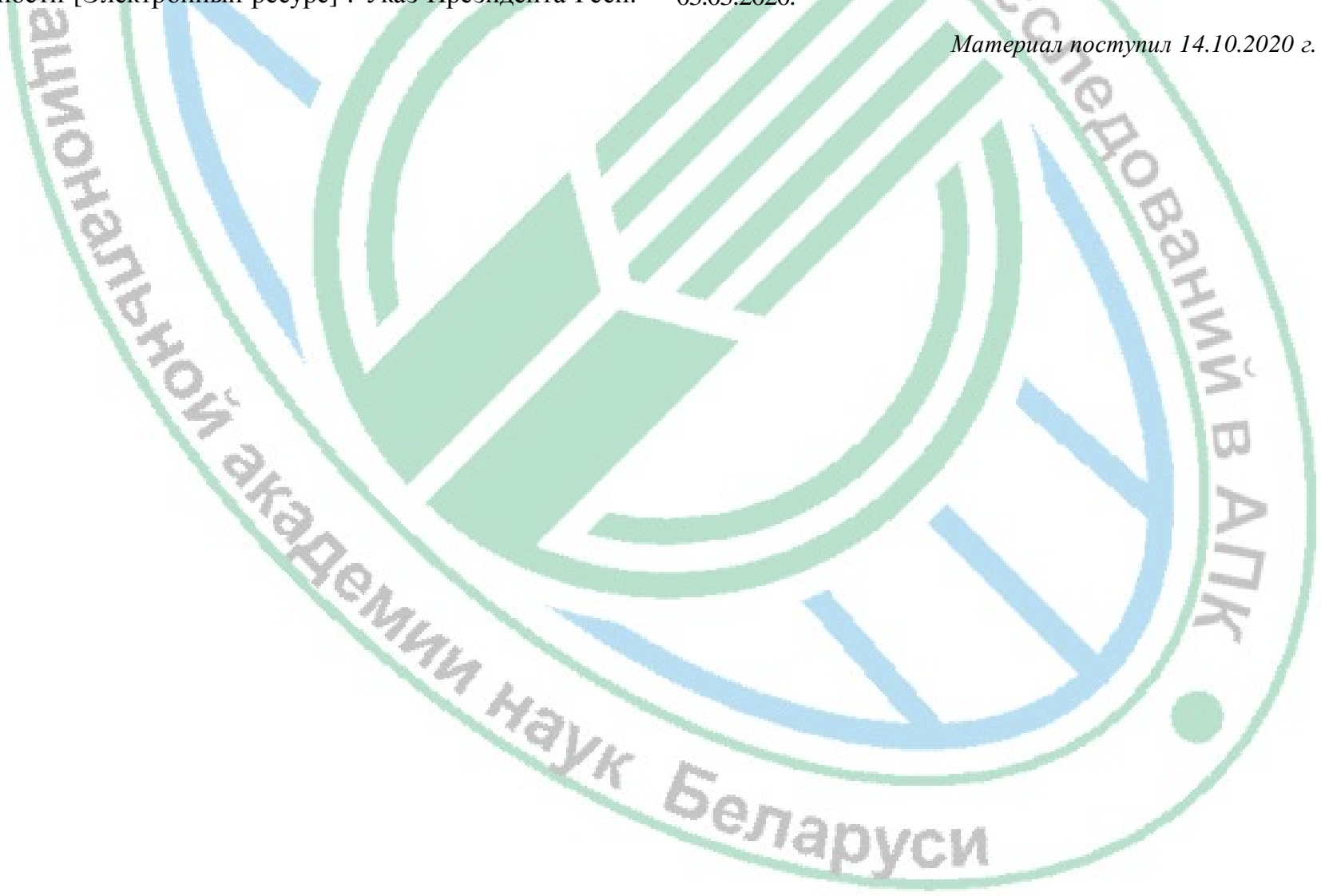

